\title{
The Role of the System of Exercises for Speaking Development
}

\author{
Zulfizar Karimova ${ }^{1 *}$ \\ ${ }^{1}$ Tashkent branch of MSU named after M.V. Lomonosov, Amir Timur str., 22, Uzbekistan
}

\begin{abstract}
This article highlights the need to use a system of exercises for the development of oral speech. Also, in this paper, various points of view of scientists are considered, information is analyzed and own arguments are given regarding the use of a system of exercises in English classes to improve oral speech. The relevance of this article lies in the fact that it gives the concept of some types and kinds of exercises, considers several types of exercises, as well as techniques with which teachers can effectively improve the oral speech of students. In the conclusion, there are practical examples of exercises that correspond to different levels of students' training.
\end{abstract}

\section{Introduction}

In the last decade, in connection with the orientation towards the practical mastery of a foreign language, the idea has been increasingly persistent that we teach in educational establishments not language, but speech (oral and written), consequently far-reaching conclusions are drawn from this.

Before deciding whether such a change of concepts is fair, it is necessary to try to find out what caused it. It is known that in the distant past, when the methodology of foreign languages began to crystallize as an independent pedagogical branch of science, teaching a language was understood primarily and mainly as teaching its grammar. Speech training was carried out as needed outside the secondary school. Then, at the end of the last century, when there was a significantly greater need for persons who practically speak a foreign language, methods appeared that equated teaching a foreign language with teaching a native one. Moreover, since the child learns the native language without specially studying its grammar, they tried to teach a foreign language, without telling him any rules (neither lexical nor grammatical). Representatives of these methods, known in the history of the method as natural, without being very sophisticated in the science of language, announced in broadcast advertisements about a new method of teaching a language without learning its grammar.

Since grammar is very abstract, and its study usually does not attract people who do not have a penchant for philology, this way of teaching a language (without studying its grammar) turned out to be very attractive and therefore won a large number of supporters. But since grammar is one of the integral parts of the language and therefore it is impossible to learn a language without learning its grammar, therefore, it was only a question of whether to learn it consciously or not, that is, the way children learn their native language. One of the most significant gaps in the methodology of teaching foreign languages is the lack of an ordered system of exercises, although very interesting attempts have been made to create it.

\section{Methods}

First of all, we should mention the system of exercises proposed by the representative of the direct method, B. Eggert and his work "Regularities underlying exercises for teaching foreign languages", which systematizes the views of this direction in the methodology. B. Eggert established a number of regularities, of which the following are still, of the greatest interest today:

a) the nature of the exercises should match the acquired skills, i.e. to teach the student the comprehension skills you need to offer him appropriate special exercises, for teaching speaking - exercises for speaking and so on. As each exercise being focused on the development of any speech activity, at the same time contains elements common to other activities, for the development of this language activity can be used and not special exercises. b) the meaning and use of language forms is best learned in the course of activities and in appropriate situations that are close to students and arouse their interest.

c) Global assimilation of language forms should be accompanied by an analysis of their components.

d) any new language phenomenon is better assimilated as a result of comparison with what is already known, including from the native language.

e) any new linguistic phenomenon is better understood if it is placed in different contexts.

f) when learning a language, the main role belongs to oral exercises, which are necessary for the development of any type of speech activity.

All exercises B. Eggert divides into exercises in speech activity (speaking, listening, reading, and writing) and aspect exercises for mastering vocabulary, grammar, and phonetics. 
Also of great interest is the system of exercises developed by G. Palmer, mainly for reproductive language acquisition. G. Palmer distinguishes between receptive and reproductive exercises. The former are divided into unconscious and conscious exercises. The task of unconscious exercises is to draw students ' attention to the General content of the phrases spoken by the teacher, regardless of their form and meaning of individual words. This type of exercise also includes exercises in the execution of orders (imperative drill). Conscious exercises should focus students ' attention on specific language phenomena (phonetic, grammatical, and lexical). The second type of exercises (receptive and reproductive) involves not only perception, but also reproduction of speech by students. There are three types of exercises: repetition following the teacher, conditional conversation, in which students mainly answer questions posed by the teacher, and natural conversation on various topics of everyday life. To the system of exercises described above, G. Palmer added wildcard tables, which then played an important role in subsequent indirect methods.

The first methodologist who paid special attention to the development of the theory of the system of exercises was Professor I. A. Gruzinskaya. She built her system of exercises based on the goal of teaching: to teach students a comprehensive mastery of the language (oral speech, reading and writing). To do this, she considered it necessary to create exercises that would cover all aspects of the language (vocabulary, grammar, and phonetics) and correspond to the mental processes that occur during its assimilation recognition, memorization, and reproduction. In accordance with this, I. A. Gruzinskaya put forward the following requirements for the system of exercises:

1. Sequence of exercises. Every new linguistic phenomenon must pass three stages of assimilation: a) receptive, this offers exercises in identifying, selecting, and grouping;

b) semi-reproductive - semi-free playback of this linguistic material, which are recommended a variety of exercises by analogy with the partial modification of the sample;

c) reproductive, which is the final stage of mastering of language skills and requires the ability to arbitrarily (without prompting) to reproduce a particular phenomenon of language to express his thoughts.

The last two stages-semi-free reproduction and random reproduction-in addition to exercises aimed at consolidating certain types of language knowledge should also include all the variety of exercises aimed at creating active skills.

2. Consistency in the application of various types of exercises. For each year of study, reference types of exercises should be selected, which should be repeated from lesson to lesson. Along with them (but in a smaller number), other exercises can be offered that would help to master this language phenomenon from all sides, in its various aspects.

3. Continuity of exercise types. Along with the obligatory continuity and repeatability of some of the main types of exercises, it is necessary to steadily expand their range and modify their content. I. A. Gruzinskaya distinguishes the following four types of exercises:

1. phonetic-spelling;

2. grammatical;

3. vocabulary;

4. exercises in creating active skills.

Within these types, the sequence is strictly observed, which is formulated in the above requirements: first, receptive exercises are given, where the student's task is to learn or choose a phenomenon from the language material given to him. They are followed by semi-productive exercises in which the sample is supplemented or partially modified. Last of all, the student is offered exercises in which he should independently reproduce the completed language material.

A more detailed acquaintance with the system of exercises proposed by I. A. Gruzinskaya leads to the conclusion that the main attention is paid to language exercises, after completing which students will be able to master oral and written speech within the requirements of the program.

In recent years, a number of studies have been devoted to the exercise system. Some develop the ideas of I. A. Gruzinskaya, such as Z. M. Lyubimova, N. B. Sokolova, P. B. Gurvich and others. They pay considerable attention to aspects of the language. Other scientists, such as, M. S. Ilyin, B. A. Lapidus, etc, build their system of exercises on a functional basis, giving preference to speech exercises.

P. B. Gurvich divides exercises into formal, formalmeaningful, meaningful-formal and meaningful. $\mathrm{He}$ considers most exercises with isolated words to be formal (word analysis, memorizing words, declension of nouns, etc., conjugation of verbs, grouping words, etc.).

Formal-content or formal-meaningful exercises are exercises that focus on the form associated with a particular content context (selecting words to describe something, paraphrasing, adding missing words, creating situations with these words, etc.).

Content-formal or meaningful-formal exercises are exercises in which the main attention is paid to the content, but at the same time the educational nature of speech actions is realized, the so-called conditionalcommunicative exercises. Content exercises are exercises in which all attention is focused on the content, and students do not receive any special lexical tasks ("natural" dialogue, retelling, narration, etc.).

Let us now briefly discuss the systems of exercises based on the functional principle. So, M. S. Ilyin, for example, distinguishes between two main types of exercises: pre-speech and speech exercises. According to M. S. Ilyin, the first type of exercises includes all exercises related to the development of grammatical and phonetic skills, as well as non -automated components of the act of speech-the choice of a sign in accordance with the situation. The second type includes exercises that develop speech.

B. A. Lapidus distinguishes two types of exercises in the system of exercises: the first is exercises for 
purposeful activation of language material and the second is exercises for non-stimulated activation of language material in the conditions of natural speech practice or approaching it. The first type includes: purely training exercises, elementary combined exercises (statements in accordance with a request or order, speech on a given structural skeleton, etc.) and combined exercises (without food with a given language material).

The second type of exercises includes exercises for unregulated activation of language material in the context of speech practice at a higher level (discussion, etc.).

B. A.Lapidus rejects exercises that require formal operations, and those where students ' attention is focused only on learning the form. In his opinion, it is also impractical to widely use exercises in which logical action (for example, opening parentheses) is not combined with speech.

In conclusion, the author lists the criteria for the effectiveness of exercises that he has five: the degree of mental activity of students; the degree of compliance with psychological conditions exercise conditions, typical of real communication; the degree of independent working on the production of the phenomenon; the efficiency of the exercises; coverage of students in the group exercise.

Consider the opinion of another scientist, E. I. Passov, who contrasts the speech system with the language system and believes that only communicative exercises are needed to master the language. They are based on three principles: the principle of imitation of the speaker's communicative task, the principle of analogy in the assimilation of grammatical forms, and the principle of the connection of form with its function in speech.

Communication exercises differ in their composition, method of implementation, and attitudes. According to the composition, there are five types of exercises: binomial (consisting of two replicas), threeterm, expanded, complex and thematic. According to the method of execution there are four types of exercises: imitative, wildcard, paraphrasing, and reproductive. Exercises are divided into four types: interrogative, stating, negative, and motivational.

\section{Results}

However, despite a number of advantages that the works have listed above, they also have some common disadvantages:

1. The system itself is not defined and, as a rule, the requirements for it are not formulated in general: in particular, it does not show how its individual elements are related to each other.

2. The described systems do not take into account all the mental processes that are necessary for language acquisition and speech development.

3. It is not defined what types of exercises make up the system, and it is not shown what the specifics of each type of exercise are (their similarities and differences). Types and kinds of exercises are mixed.
4. The completeness of the system is violated, because, firstly, it is often reduced to two types of exercises: language and speech, or preparatory and speech, and, secondly, some types of exercises (mechanical, bilingual) are rejected or underestimated without sufficient grounds and the role of others (monolingual, communicative) is exaggerated.

Obviously, a system of exercises for teaching a foreign language should be understood as a set of types and kinds of exercises that are related to each other by purpose, material and method of their implementation and arranged according to the principle of composition and subordination. Each element of the system is irreplaceable and represents a binomial opposition.

Types of exercises are divided into types, which should be arranged in order of increasing difficulties. The following requirements should be applied to the exercise system. It should:

1. develop cognitive processes of the individual (thinking, memory, imagination);

2. consider the purpose, material, and method of performing exercises;

3. develop and ensure the assimilation of all aspects of the language and all types of language activities;

4. include all types and kinds of exercises, each of which should have its own specifics (irreplaceability of system elements);

5. communicate between elements of the system according to the principle of composition or subordination; each element of the system must represent a binomial (binary) opposition;

6. arrange kinds and types of exercises according to the degree of increasing difficulties. When classifying exercises, as a rule, terms with a negative characteristic should not be used.

The system of exercises should be aimed at mastering all aspects of the language, because onesided preferential attention to one of them - grammar or vocabulary-leads to the fact that speech is impoverished or full of errors that are later difficult to correct. The completeness of the system is achieved only if all analyzers participate in speech development from the very beginning of training, and oral speech is supplemented by reading and writing.

Within the system, you should distinguish between types and kinds of exercises that are not hierarchically related. Kinds of exercises are divided into types, which in turn can be represented by various options.

They are practically used by teachers when teaching the language. Not being able to show how the system described above functions in different types of academic institutions, we analyzed the functioning of the exercise system in non-linguistic universities, where the material studied is more stable; we will try to show the effectiveness of using the proposed exercise system for the development of oral speech among students of non-linguistic Universities.

\section{Discussions}

However, it seems appropriate to cover some general issues first. These include the following: 1. Motivation 
for learning. 2. Use of technical means. 3. The uniformity of the exercises in each class. 4 . The ratio of the new and the already traversed material and the amount of exercise. 5. The nature of the exercises depends on the language being studied.

\section{Motivation for learning}

The success of practical mastery of a foreign language depends on how motivated it is in the eyes of students. Motivation can be natural or artificial. Natural motivation can be created only in the senior years, when students have already mastered the basics of the language and will be able to use them in their practical activities — read literature in a foreign language and listen to podcasts and videocasts, radio and TV.

In junior years of university, motivation should be created artificially, namely by interest in the learning process itself. This interest can include three components: encouragement in the form of a good grade, interest in the subject, in the process of mastering new knowledge, skills and abilities, and the associated satisfaction with the results obtained.

Encouragement in a foreign language classes is no different from encouragement in other subjects and therefore does not require any additional explanations. Interest in the subject "Foreign language" has its own characteristics. In other Humanities subjects, the content of the science being studied, even if it is prepared for school education in an academic subject, is of interest. The science of language (General or particular linguistics) is not studied at school, and the theoretical information on phonetics, grammar, and lexicology that is communicated to students is extremely brief and sketchy, and therefore, obviously, does not arouse much interest in them. However, when teaching a language, we introduce students to certain activities, which can arouse interest if the teacher uses appropriate methodological techniques, and students feel the results of their activities.

Therefore, certain techniques and a specially designed system of exercises can arouse interest in this activity. Exercises are interesting if they involve mental work, are feasible and accessible. However, not all exercises require students to be mentally active. When learning a language, some phenomena have to be memorized mechanically, without the participation of mental operations.

This means memorizing the forms of words that cannot be explained without involving the history of the language, which, as is well known, is not studied in non-linguistic Universities. Special mention should be made of the methodical techniques used by the teacher. Some teachers have a tendency to turn foreign language classes into a game, as the well-known German methodologist M. Walter, but this is hardly advisable, firstly, there are not always conditions for this, and secondly, the student should be aware that a foreign language is as important a subject as any other is, and it should be treated seriously as well.

To arouse interest to classes, you can sometimes involve a game, but this should be an episode, and not the norm. The norm should be such methodological techniques that would appeal to the active thinking activity of students. Interest in classes can be enhanced by skillful use of technical means.

\section{Use of technical means}

Technical means are divided into visual (projector), audio (tape recorder, radio, speaker) and audio-visual (TV, tablet). The use of technical means, firstly, significantly improves visual and auditory perception and memorization of the studied language material, secondly, facilitates speech development and, thirdly, contributes to the involvement of all students in the work. They can be used both in the classroom and during extracurricular activities when students perform individual tasks. The latter make it possible to take into account the individual characteristics of students (their abilities, home conditions, etc.).

In the course of classes, technical means can be used, first, to concretize the studied language phenomena, second, to create appropriate situations that facilitate the process of speaking a foreign language, and third, and perhaps most importantly, to master the ability to understand speech by ear. We have already mentioned above that understanding speech by ear is a huge incentive for practical mastery of oral speech, and here technical means are absolutely indispensable.

Mastering the understanding of speech by hearing is associated with understanding different sound colors, different tempo, timbre of voice (male or female), intonation, i.e. those conditions that the teacher cannot create without resorting to technical means. Not to mention that not all teachers are proficient in idiomatic speech in the taught foreign language. In addition, the perception of the teacher's speech occurs without those hindrances that are characteristic of mechanical speech, namely, they will have to deal with most of all in practical life. By listening to a dubbed movie or podcast and understanding its content, students begin to feel the practical benefits of learning a foreign language - an incentive that can hardly be overemphasized. It increases interest in classes, which, in turn, affects the quality of learning the material and contributes to its involuntary memorization.

\section{The uniformity of the exercises}

One of the significant disadvantages of the exercises offered by many text books is that they are either too monotonous and are reduced from lesson to lesson to a repetitive formula: "Read, translate and learn words" or, on the contrary, are too diverse - new exercises appear in each part, and old ones are forgotten. The only exceptions are mechanical, aspect, and choral exercises, which are no longer necessary in senior years. As for the types and kinds of exercises, they should be distributed according to their difficulty. The difficulty of the exercise depends, depending on the kind and type of exercise, on the material to be learned, and on the thought and mnemic processes involved in the exercise.

For each course, you need to determine the leading type of exercise, which can be represented by different types and supplemented with other types, but not the main ones for this course. 
4. The ratio of new and already completed material and the number of exercises

The ratio of new and old material is extremely important for its assimilation and is closely related to the problem of repetition and the strength of mastery, skills and abilities. In each lesson, exercises that contain material that you have already completed must be several times larger than those that contain the new material. New material should always be based on the old, and each time it should be offered in a new form, so as not to lose the charm of assimilation. One of the biggest problems is that the material being studied is not well understood, and therefore it is necessary to conduct special classes dedicated to the repetition of what has been passed.

K. D.Ushinsky was right when he wrote: "Repetition in order to remember what has been forgotten already shows a lack of learning and generally poor teaching in school. Obviously, the issue of revising the distribution of educational material is long overdue. It would seem that, for example, the lexical material is very small. If this dictionary is divided by the total number of hours devoted to learning a foreign language in non-linguistic Universities, then less than three new words are added to each lesson. If we further compare this number with the number that intensive students can remember in one lesson - 200 (although they are in completely different conditions), it will still become clear that the point is not in the amount of material, but in the inexpediency of the methodological techniques used, in an insufficiently thought-out system of exercises. After all, almost all universities complain that even this more than modest minimum of words (1500) students learns only $50 \%$. Often, we have to deal with the fact that students spend a lot of time doing exercises, not because they are difficult and contain a lot of new material, but because the material they have learned is poorly understood, forgotten, and the old material is again perceived as new. The teacher completed the program at one time, but the student did not acquire any knowledge, skills and abilities. Memorizing the material and acquiring the necessary skills and abilities to use it is also associated with the number of exercises offered by the teacher. This question has not yet been completely tested experimentally and depends more on how well the student has mastered the previously learned material.

The experience of composing textbooks has shown that the material is fully absorbed,even if it has $100 \%$ repeatability. This principle is not easy to observe in all textbooks, but if you agree with the recommendations on the subject set out above, then compliance with this principle is quite possible with the concentric development of this topic. If now it is difficult to name the exact number of exercises that should be given to students for each lesson, then we can still say that it can be increased compared to what is offered in current textbooks.

There are two other factors that should be taken into account when drawing up exercises. First, that all reproductively acquired material is then assimilated receptively, i.e. that reproductive exercises are followed by receptive ones. Secondly, to take into account both voluntary and involuntary attention of students. The first requirement is due to the fact that all material intended for reproductive assimilation must also be assimilated receptively. Earlier, when describing reproductive and receptive exercises, we have already found out that each of these types of exercises has its own specifics, its own function, and one type of exercise cannot be replaced by another if this material must be learned both reproductively and receptively. As for voluntary and involuntary attention and the associated voluntary and involuntary memorization, there is some underestimation of students ' perception of the material that is not consciously memorized. As the latest psychological studies and University experience show, a student remembers some of the language material involuntarily, without special memorization, due to the fact that this material is of interest to him or is repeatedly repeated in various situations. When composing exercises, this feature of memory should be taken into account. To ensure that this process does not occur only spontaneously and chaotically, it is necessary to provide in advance what material should be memorized, and what the student can remember without spending special effort on it. It seems that for mastering grammatical phenomena, it is preferable to use arbitrary attention. Some parts of the vocabulary may be remembered involuntarily. Pronouncing norms must first be acquired consciously and only during subsequent training can serve as an object of involuntary attention.

5. The nature of exercises depending on the language being studied

\section{Practical exercises and conclusion}

The proposed system of exercises can be used when learning any language, but the ratio of individual types of exercises and their specific weight depend on the characteristics of the language being studied. For example, when learning German with its fairly welldeveloped system of declension and conjugation, much attention should be paid to morphology, and therefore the proportion of aspect and mechanical exercises will be greater than when learning English. French occupies an intermediate position, although it tends more towards English. When teaching French and English, syntactic language exercises will prevail over those given for mastering the syntax of the German language.

When teaching French and English, writing exercises play a greater role than when teaching German, since the spelling of these languages is based on a historical principle, and there are no rules in modern language (especially in English) that would help to spell a word correctly. In French, the correct spelling of words is also associated with the distinction of verb forms, plural nouns, etc. Significant differences are also observed in the vocabulary. In German, the composition of vocabulary for at least the first two 
years of study is largely determined by the grammar being studied.

The choice of many verbs depends on the knowledge of the case system of nouns, as well as their belonging to the weak or strong conjugation. In English, the use of certain adverbs is impossible without mastering the corresponding verb forms. In the French language sequence for the learning of verbs is dictated by their belonging to a particular type of conjugation. The choice of words also depends on their usage in the language being studied. For example, verbs with different prefixes are very common in German, which is not observed in either English or French. Verbs like faire, prendre, and take are widely used in French and English, prendre, take, while their counterparts in German are not so widely used.

In order for the teacher to have a clearer idea of how to use the proposed system of exercises in practice, the following examples of exercises are given.

These exercises do not represent a system of exercises for a particular course. It can only be shown in a textbook that provides instruction not only in oral speech, but also in reading and writing. This list of exercises has the following objectives:

a) to show what kinds and types of exercises should prevail in a particular class; the number of language exercises, in particular, is gradually decreasing;

b) to illustrate the continuity of exercises between classes;

c) to demonstrate that the difficulty of exercises does not always depend on the type, but rather on the chosen type or variant, so that the order of exercises is often determined by them, and not by the type of exercise.

In our list, the order of types of exercises is determined by the prevailing type of exercises for this class. Almost every one of the presented examples of exercises (except for specially specified ones) can be performed both orally and in writing. It is up to the teacher to decide how to implement it. Since the article describes a system of exercises for teaching oral speech, the number of oral exercises will prevail, as well as the number of monolingual exercises, although bilingual (translated) exercises should also be given in a certain proportion in all courses. For the most part, each type of exercise is represented by only one option, but this does not mean that there should not be several of them. It is not possible to show all the exercise options due to their large number. The number of options will depend on how well you have studied the completed material.

These exercises are not designed for studying the entire material of the foreign language program, but are only samples, by analogy with which other versions of exercises can be compiled for mastering other language phenomena and developing other skills.

\section{Types of exercises}

\section{Comparison}

1. The repetition of questions and answers.

2. Reading in chorus (behind the teacher).

3.Making suggestions based on wildcard tables (mechanical and creative).
4. Learning by heart.

5.Making suggestions based on a sample (without replacing it).

6. Drawing up suggestions based on a sample (with the replacement of individual parts).

\section{Transformation}

1. Replacing individual parts of the offer.

2. Converting the form of words.

3. Translation from Russian to English.

\section{Extension}

4. Exercises with missing words.

1. Please, repeat:

I. What is your name? - My name is Mike.

2. Do you play tennis? - Yes, I do.

3. Does he play tennis well? - Yes, he does.

2. Read in unison: We see Ann. We see her desk. We see her books. We take her books. We have her books.

3. Make suggestions:

Give me his pencil! Do not give Kate her notebook! We want to play games in the morning he likes to read books after study she wants to go out on Sunday.

4. Learn it by heart:

I take my book, he takes his book, she takes her book, you take your book.

5. Make suggestions using the following structure:

I like to...

1.I like to speak English. 2. I like to play tennis. 3. I like to read about animals

6. Make sentences that are related in meaning to the data: It is cold today. I cannot go to the forest. I read a book at home.

7. Replace individual parts of the following sentences:

Mike often comes to my house in the evening. He often comes to see me in the evening. He often comes to see me in the afternoon.

8. Replace the highlighted words with personal pronouns in the correct form: 1 . Does Kate play games with her little sister? 2. Do you go to school with Mike? 3. Do you give your little brother your pictures?...

9. Translate into English:

We go to the University in the morning. We are going to class. In English lessons, we read and write. We play football after study.

10. Complete the missing preposition in or into:

1. I like to sit under a tree ... the forest in summer. 2. After dinner the boys run ... the yard and begin to play football. 3. They like to play football the yard.

\section{Types of exercises}

Likening 1. Reading in chorus (behind the teacher). 2. Memorizing by heart. 3.-Making suggestions based on wildcard tables or a sample. 4. Question-and-answer exercises.

Conversion 5. Form conversion. 6. Replacing individual parts of the offer. 7. Change of offers (due to changes in the situation) 8. Translation from Russian to English.

Expansion 9. Exercises with omissions. 10. Adding suggestions.

1. Read it in unison: 
He came to London late on Saturday night and went to a hotel. The next morning he got up early. After breakfast, he remembered that he had to send his sister a telegram. Therefore, he sent the telegram with the address of the hotel and then made his plans for the day.

\section{Learn it by heart:}

be — was, eat - ate, bring — brought, give gave, buy — bought, go — went, come - came, meet - met, do - did, read - read

3. Make suggestions a) using the wildcard table: I didn't go in the garden yesterday he didn't play on the excursion last week they didn't work in the yard last Sunday

б) by sample: The boys couldn't play football, because it began to rain.

4. Answer the following questions: 1. Did Mr. Black remember his address in New York? 2. Did Mr. Black's sister know his address in London? 3. Did she send him a telegram with his London address?

5. Put the selected nouns in the plural: The families of many workers live near their factory. The boy in my Russian circle knows a story about animals. The woman made the dress quickly.

6. Replace parts of the following sentences. 1. My brother came home late from work yesterday, so I could not play chess with him in the evening. 2 . There were no trams or buses yesterday evening, so we had to walk all the way home. ...

7. Change the following sentences to reflect the changed situation:

The wind began to blow. The man who walked near the lake was cold and put on his coat. Suddenly the sun began to shine...

8. Translate it into English: In the summer, I was in a holiday home. There was a small river near it and on the other side of the river, there was a forest. We went there every day....

9. Complete the missing verbs: Yesterday ... Saturday. I ... home early from university. I ... two letters and ... them on a bench for my sister. After supper I ... her dolls and ... them on my table. I ... to ... their faces. ...

10. Complete the following sentences: Last Saturday was the first of January, and we had a party at... We also had a party at... After breakfast I helped mother... I took the chairs out of all the rooms and put them...

\section{Types of exercises}

Conversion 1. Translation from Russian to English. 2. Replacing parts of the offer. 3 . The transformation of the shape of words. 4. Replacing some questions with others.

Extension 5. Exercise with missing words. 6. The story in connection with this situation. 7. Add suggestions. 8. Question-and-answer exercises.

Reduction 9. The implementation of the proposals. 10. Retelling with abbreviations and paraphrases.

1. Translate it into English:

1. Misha runs very fast. - Misha runs very fast.

2. Nina usually plays in the garden. - Nina is currently playing in the garden.
3. Mom always takes a break after work. - Hush! Mom is resting after work.

4. Anna draws best of all. - What are you drawing, Anna?

2. Replace the highlighted nouns with others: 1. I have opened the window. 2. He has cleaned his clothes. 3. We have washed our hands. ...

3. Put verbs in the past tense (Past Indefinite Tense): All the cities in Greece (to send) their best athletes to the city of Olympus, to compete in the games. Thousands of people (to come) from all parts of Greece to see the games. At that time cities in Greece (to be) not friends with each other. However, at the Olympic Games people (to be) friends. All wars between the cities (to stop)...

4. Replace the questions posed to the pictures with other ones.

5. Insert the missing verbs:

1. Now they ... their hands. - They ... already their hands. 2. Now they ... their dinner. — They ... already their dinner. 3. Now they ... chess. - They ... already chess.

(Students perform this exercise by first looking at a book and then listening.)

6. Tell us what you will be talking about with the guests from England who will visit your office next week (come up with 8-10 suggestions).

7. Finish the following sentences:

1. I cannot go with you because... 2. He ran all the way home because... 3. We have not seen him because...

8. Answer the questions:

1. Why are you laughing? 2. Why are you smiling? 3. Why are you angry with me? 4 . Why are not you working?

9. Shorten the following sentences, keeping their main meaning:

1. We have many friends everywhere in the world. 2. Nobody saw him yesterday at school. 3. Mother refused to go to the country with us last Sunday. ...

10. Tell the following text in your own words, make possible abbreviations and substitutions:

The city of Sparta was in Laconia, so people sometimes gave the Spartans the name Lacons. The Lacons never spoke much and they taught their children not to use more words than they needed. "If you listen more and speak less," they said, "you will learn many things. People that talk too much are usually not very clever!" So, it became a tradition in Laconia to try to use less words. And even now we say that an answer in not many words is a laconic answer.

\section{Types of exercises}

Extension 1. Adding suggestions. 2. The distribution of the text. 3. Answers to questions.

Conversion 4. The conversion of one form to another. 5. Translation from Russian to English.

Abbreviation 6. Shortening the text.

1. Complete the following suggestions:

1. ... because I have по money. 2. ... because I have not enough time. 3. ... because you were wrong. 4. ... because she refused to go with me. 5 . ... because she was angry with her. ... 
2. Please distribute the following suggestions: When I came to London, I went to see my uncle. I found him with his friend. My uncle invited me to have lunch. After lunch, his wife called him to the telephone. "I'm sorry," he said when he came back, "I must leave you now. I will try to be back soon. Don't go away!"

\section{Answer the questions:}

1. Where do you usually spend your holidays? 2. Where did you go last year? 3. What do you do after school? 4. Why do you learn English? 5. Whom do you sometimes write letters to? ...

4. Convert Present Continuous to Past Continuous:

When he came... (I am listening to the radio, I am writing my letter, He is reading a book...)

\section{Translate into English:}

6. Shorten the following text:

Jimmy lived alone in a little house on a hill. It was in the middle of an endless forest, and Jimmy did not have many visitors. He was a railway worker, and he had to take care of the line that came up the hill to the house and went down the other side. Trains roared up the hill and then down: they never stopped, and Jimmy paid no attention to them...

\section{Types of exercises}

Extension 1. Supplement offers. 2. Answers to questions. 3. Creating a dialog.

Abbreviation 4. Shortening the text. 5.Abbreviating text with possible conversions.

Conversion 6. translation from Russian to English.

1. Complete the following suggestions with as many options as possible:

1. The work was finished in time because... 2. The party was enjoyed by many girls though... 3. The letter was read twice but... 4. I was very tired, so...

2. Answer the following questions in two or three sentences:

1. What kind of schools are there in the your country? 2. What are you going to do when you finish school? 3. What English books have you read? 4. Who is your favourite English writer?...

3. Create a dialog (a foreigner stopped you and asked for directions...).

4. Shorten the following text: On the tenth day of my adventure, I received an invitation from the American ambassador and went to his house. He had read about me in the newspapers, of course, and was very glad to meet me. He invited me to a dinner party that he was giving that same evening. ...

5. Shorten the following text, by making possible conversions: In 1917, the United States joined the other imperialist countries in the struggle for world power. John Reed criticized it. He insisted that it was a Wall Street war, not a war of the American people. He gave lectures against the war, his voice was heard everywhere, and the capitalists were frightened. ...

6. Translate it into English:

\section{Types of exercises}

Assimilation 1. Making up a story similar to the one you read.

Transformation 2. Expressing the same thoughts by other linguistic means.

Abbreviation 3. Drawing up a plan for the text.
Expansion 4. Story according to plan. 5. Creating a dialog for this situation.

1. Read the text and create a similar story using the data provided in the illustration.

2. Express the same thoughts differently (in other words and constructions):

According to some historians, there was a young man in Rome who won the admiration of the whole city by his ability as a swimmer. When some people said "he swims like a fish", others used to answer: "No, the strongest fish swims like him!" 3. Make a plan for the text you read.

4. Tell us the text for this plan

5. Create a dialog using the specified situation.

Therefore, in order to successfully develop oral speech, it is necessary to create certain conditions: knowledge of the topic, knowledge of the relevant language material, understanding of the situation and the presence of an incentive for utterance.

However, we must not forget that all speech preparation, i.e. most of the exercises aimed at developing oral speech skills, is performed during extracurricular activities, in the form of external or internal speech, in the form of language or speech exercises. Without them, it is impossible to speak in class, it is impossible to have an educational or natural dialogue.

When determining the purpose of teaching oral speech, you should finally have a clear idea of the persons who will conduct the conversation and where it will take place - in the country of the language being studied or in their own country.

\section{References}

1. B. Eggert, O Bungsgesetze im frcmdsprachlichen Unterricht,Leipzig, 186. (2006)

2. I. Gruzinskaya, Exercises in 5-8 grades of secondary school, Foreign languages at school, (1998)

3. P. B. Gurvich, Fundamentals of teaching oral speech at language faculties, Vladimir State Pedagogical Institute, II. (2004)

4. E.I Passov, Communicative exercises. - M (2001)

5. K.D. Ushinskiy, Man as a subject of education. Experience in pedagogical anthropology, Pedagogical course programs for women's educational institutions, 544. (2005)

6. M. Fleming, F. Goullier, E. Thürmann, H. Vollmer, The language dimension in all subjects $A$ Handbook for Curriculum development and teacher training, Council of Europe. (2015)

7. Sh. Torky, The Effectiveness of a Task-Based Instruction program in Developing the English Language Speaking Skills of Secondary Stage Students, Cambridge, 4th ed, 23. (2006)

8. G. Escudero; D. J. Cutiopala; Janneth A. Caisaguano; L. Gallegos, A comprehensible overview of EFL students' drawbacks to produce oral communication,41,3. (2020)

9. A. Aripova, Kh. Khodjayeva, N. Yuldasheva, Methods, aspects and components of teaching the 
Uzbek (Russian) language as a foreign language on the experience of foreign students, Advance Scientific Research, 2019 DOI: http://dx.doi.org/10.31838/jcr.07.04.75

10. A. Al-Roud, Problems of English Speaking Skill that University Students Encounter from Their Perspectives, British Journal of Education, Society \& Behavioural Science, 18 (3), 1-9. (2016)

DOI: https://doi.org/10.9734/bjesbs/2016/28404

11. M.S. Ilyin, Fundamentals of Foreign Language Exercise Theory, Moscow, 152. (2018)

12. B. A. Lapidus, Intensification of the process of teaching a foreign language oral speech, Moscow, 55. (1970)

13. U. Yuldashova, M. Bozorova, N. Mansurova, Z. Ahmedova, A. Shoazizova, Language teaching methods: theory and practice, Journal of Critical Reviews, Vol 7, Issue 5. (2020) DOI: http://dx.doi.org/10.31838/jcr.07.05.157

14. M. Kh. Akhmedova, Problems of typology of exercises for the development of foreign language speech of students, 2, 480-483.(2015)

15. L.R. Duncan, C.R.Hall, P.M. Wilson, Exercise motivation: a cross-sectional analysis examining its relationships with frequency, intensity, and duration of exercise. Int J Behav Nutr Phys Act 7, 7. (2010) DOI: https://doi.org/10.1186/1479-5868-7-7

16. E. Dorgu, Different Teaching Methods: A Panacea for Effective Curriculum Implementation in the Classroom, International Journal of Secondary Education, 3(6), 77. (2016) DOI: https://doi.org/10.11648/j.ijsedu.s.2015030601.13

17. H. A Alharbi, Improving Students' English Speaking Proficiency in Saudi Public Schools. International Journal of Instruction, $8(\mathbf{1})$, 105-116. (2016)

18. A.M. Gaifutdinov, Guiding didactic principles in the knowledge of the domestic pedagogy of the second half $x x$-the beginning of the xxi century,Historical and pedagogical journal, 1, 112. (2014)

19. S. Al. Hosni, Problems and Difficulties of Speaking That Encounter English Language Students at Al Quds Open University. International Journal of Humanities and Social Science Invention, 5(12), 96-101. (2016)

20. L. A. Hendra \& C. Jones, Motivating learners with immersive speaking tasks. Part of the Cambridge Papers in ELT series, 16. (2018)

21. A. Lin, Bilingual Education in Different Contexts: Principles and Practice, Bilingual Education, 27. (2009)DOI:10.5790/hongkong/9789622099586.00 3.0002

22. S.Bentin, T.Allison, A. Puce, E. Perez, \& G. McCarthy, Electrophysiological studies of face perception in humans. Journal of Cognitive Neuroscience, 8, 551-565. (2010)

DOI: $10.1162 /$ jocn.1996.8.6.551
23. H. Fry, S. Ketteridge, S. Marshall, A Handbook for Teaching and Learning in Higher Education Enhancing Academic Practice, 202. (2008)

24. Merryanna L. Swartz, Masoud Yazdani, Intelligent Tutoring Systems for Foreign Language Learning, Springer, Berlin, Heidelberg, (2012) DOI: https://doi.org/10.1007/978-3-642-77202-3

25. M. I. Hossain, Teaching Productive Skills to the Students: A Secondary Level Scenario, BRAC University, Dhaka, Bangladesh, 34. (2015) 